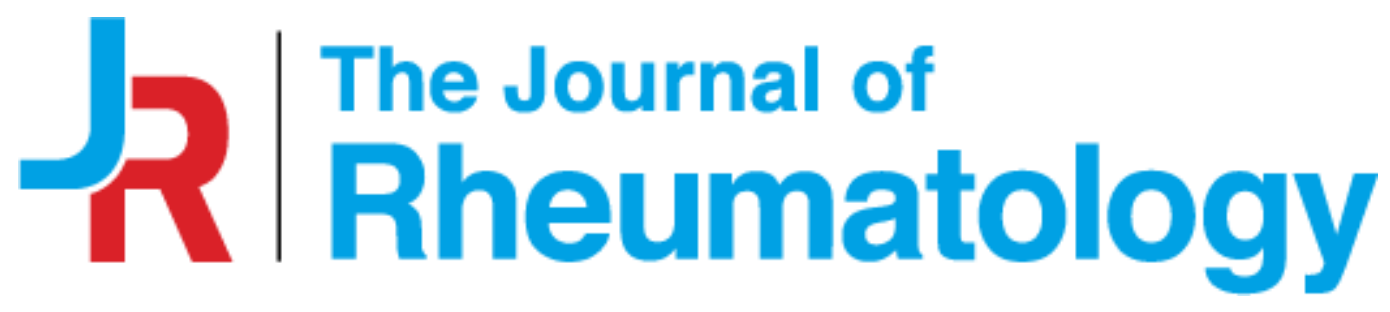

The Journal of Rheumatology

Volume 44, no. 5

Defining Outcome Measures for Psoriatic Arthritis: A Report from the GRAPPA-OMERACT Working Group

Alexis Ogdie, Maarten de Wit, Kristina Callis Duffin, Willemina Campbell, Jeffrey Chau, Laura C. Coates, Lihi Eder, Musaab Elmamoun, Oliver FitzGerald, Dafna D. Gladman, Niti Goel, Jana James, Umut Kalyoncu, John Latella, Chris Lindsay, Philip J. Mease, Denis O'Sullivan, Ingrid Steinkoenig, Vibeke Strand, William Tillett and Ana-Maria Orbai

J Rheumatol 2017;44;697-700

http://www.jrheum.org/content/44/5/697

1. Sign up for TOCs and other alerts

http://www.jrheum.org/alerts

2. Information on Subscriptions

http://jrheum.com/faq

3. Information on permissions/orders of reprints http://jrheum.com/reprints_permissions

The Journal of Rheumatology is a monthly international serial edited by Earl D. Silverman featuring research articles on clinical subjects from scientists working in rheumatology and related fields. 


\title{
Defining Outcome Measures for Psoriatic Arthritis: A Report from the GRAPPA-OMERACT Working Group
}

\author{
Alexis Ogdie, Maarten de Wit, Kristina Callis Duffin, Willemina Campbell, Jeffrey Chau, \\ Laura C. Coates, Lihi Eder, Musaab Elmamoun, Oliver FitzGerald, Dafna D. Gladman, \\ Niti Goel, Jana James, Umut Kalyoncu, John Latella, Chris Lindsay, Philip J. Mease, \\ Denis O'Sullivan, Ingrid Steinkoenig, Vibeke Strand, William Tillett, and Ana-Maria Orbai
}

\begin{abstract}
The Group for Research and Assessment of Psoriasis and Psoriatic Arthritis (GRAPPA)-Outcome Measures in Rheumatology (OMERACT) Psoriatic Arthritis (PsA) Core Set working group recently published the updated 2016 psoriatic arthritis (PsA) core domain set, a set of disease features that should be measured in all clinical trials. At the GRAPPA annual meeting in July 2016, the PsA working group presented the updated PsA core domain set endorsed by $90 \%$ of participants at OMERACT in May 2016 and drafted a roadmap for the development of the PsA core outcome measurement set. In this manuscript, we review the development process of the PsA core domain set and the ongoing and proposed work streams for development of a PsA core measurement set. (J Rheumatol 2017; 44:697-700; doi:10.3899/jrheum.170150)
\end{abstract}

Key Indexing Terms: PSORIATIC ARTHRITIS GRAPPA

PSORIASIS

\section{OUTCOME MEASURES} OMERACT
Outcome measure development has rapidly progressed over the past 10 years and so, too, has our knowledge of psoriatic arthritis (PsA) pathophysiology and the multiple facets of life affected by this disease ${ }^{1,2}$. The Group for Research and Assessment of Psoriasis and Psoriatic Arthritis (GRAPPA)-Outcome Measures in Rheumatology (OMERACT) PsA working group developed a Core Domain Set to be measured in randomized controlled trials (RCT) and longi-
From Medicine and Epidemiology, Perelman School of Medicine, University of Pennsylvania, Philadelphia, Pennsylvania; University of Utah, Salt Lake City, Utah; QuintilesIMS, Denver, Colorado; Duke University School of Medicine, Durham, North Carolina; Rheumatology Research, Swedish Medical Center; University of Washington School of Medicine, Seattle, Washington; International Dermatology Outcome Measurers, West Granby, Connecticut; Cleveland Clinic, Cleveland, Ohio; Division of Immunology/Rheumatology, Stanford University School of Medicine, Palo Alto, California; Johns Hopkins University School of Medicine; Psoriatic Arthritis Program, Johns Hopkins Arthritis Center, Baltimore, Maryland, USA; VU Medical Centre, Amsterdam, the Netherlands; University of Toronto; Krembil Research Institute; Psoriatic Disease Program, Toronto Western Hospital; Women's College Research Institute, Women's College Hospital, Toronto, Ontario, Canada; Hong Kong Psoriatic Arthritis Association, Hong Kong, China; UK National Institute for Health Research (NIHR), Leeds; Institute of Rheumatic and Musculoskeletal Medicine, University of Leeds, Leeds; Royal United Hospital; Royal United Hospital; Pharmacy and Pharmacology, University of Bath, UK; Newman Clinical Research Professor, St. Vincent's University Hospital and University College Dublin; Our Lady's Hospice and Care Services, Dublin, Ireland; Internal Medicine, Division of Rheumatology, Hacettepe University Faculty of Medicine, Ankara, Turkey. AO was supported by US National Institutes of Health K23 AR063764 and the Rheumatology Research Foundation. AMO was supported in part by a Scientist Development Award from the Rheumatology Research Foundation and the Johns Hopkins Arthritis Center Discovery Fund.

As part of the supplement series GRAPPA 2016, this report was reviewed internally and approved by the Guest Editors for integrity, accuracy, and consistency with scientific and ethical standards.

A. Ogdie, MD, Assistant Professor of Medicine and Epidemiology, Perelman School of Medicine, University of Pennsylvania; M. de Wit, PhD, Patient Research Partner, VU Medical Centre; K. Callis Duffin, MD, University of Utah; W. Campbell, BEd LLB, Patient Research Partner,
Toronto Western Hospital; J. Chau, BA, MCS, Patient Research Partner, Hong Kong Psoriatic Arthritis Association; L.C. Coates, MBChB, PhD, Clinical Lecturer, NIHR, Leeds Institute of Rheumatic and Musculoskeletal Medicine, University of Leeds; L. Eder, MD, PhD, Assistant Professor of Medicine, Women's College Research Institute, Women's College Hospital; M. Elmamoun, MBBS, MRCPI, Fellow, University of Toronto, Toronto Western Hospital; O. FitzGerald, MD, FRCPI, FRCP $(U K)$, Newman Clinical Research Professor, St. Vincent's University Hospital and University College Dublin; D.D. Gladman, MD, FRCPC, Professor of Medicine, University of Toronto, and Senior Scientist, Krembil Research Institute, and Director, Psoriatic Disease Program, Toronto Western Hospital; N. Goel, MD, Patient Research Partner, Vice President, Advisory Services, QuintilesIMS, and Adjunct Assistant Professor, Duke University School of Medicine; J. James, Patient Research Partner, Royal United Hospital; U. Kalyoncu, MD, Assistant Professor of Internal Medicine, Division of Rheumatology, Hacettepe University Faculty of Medicine; J. Latella, BS, MS, Patient Research Partner, and Board Member, International Dermatology Outcome Measurers; C. Lindsay, PharmD, Patient Research Partner; P.J. Mease, MD, Rheumatology Research, Swedish Medical Center, and Clinical Professor, University of Washington School of Medicine; D. O'Sullivan, BE, Patient Research Partner, Our Lady's Hospice and Care Services; I. Steinkoenig, BA, Patient Research Partner, Cleveland Clinic; V. Strand, MD, Division of Immunology/Rheumatology, Stanford University School of Medicine; W. Tillett, $M B C h B, P h D$, Consultant Rheumatologist, Senior Lecturer, Royal United Hospital, and Pharmacy and Pharmacology, University of Bath; A.M. Orbai, MD, MHS, Assistant Professor of Medicine, Johns Hopkins University School of Medicine, and Director, Psoriatic Arthritis Program, Johns Hopkins Arthritis Center. Address correspondence to Dr. A. Ogdie, Assistant Professor of Medicine and Epidemiology, Division of Rheumatology, Center for Clinical Epidemiology and Biostatistics, University of Pennsylvania, White Building, Room 5023, 3400 Spruce St., Philadelphia, Pennsylvania 19104, USA.E-mail: alexis.ogdie@uphs.upenn.edu 
tudinal observational studies (LOS), and is working to develop a Core Outcome Measurement Set. At the GRAPPA annual meeting in July 2016, the working group presented results and next steps.

\section{PsA Updated Core Domain Set}

The PsA working group included an international group of rheumatologists, dermatologists, patient research partners (PRP), methodologists, and 2 fellows. The working group developed a plan to update the 2006 PsA Core Domain Set ${ }^{3}$ following the OMERACT meeting in May $2014^{4}$. At the meeting, OMERACT participants voted that the PsA core domain set should be revised because of the updated knowledge about PsA (including the importance of individual disease manifestations), the need to incorporate patient input, and the new OMERACT "Filter 2.0" methodology (a set of guidelines proposed by OMERACT for development of core domain sets) $)^{5}$. The group developed a plan to address these issues through individual work streams that culminated in a series of consensus activities. PRP were included in all phases including 1 PRP on the steering committee, and at least 1 PRP was involved in the planning and interpretation of each of the work streams ${ }^{6,7}$.

Using the OMERACT Filter 2.0 framework, the working group performed an update (2010-2015) of the systematic literature review of domains measured in RCT and $\mathrm{LOS}^{8}$. Next, patient domains were identified through international focus groups (130 patients in 7 countries). A total of 39 domains were identified from focus groups and literature review. In a phone conference, the working group discussed how to organize and describe these 39 domains in patients' words. Patient and provider Delphi surveys were then sent to 75 patients and 125 physicians (rheumatologists and dermatologists) to rate the importance of the items for measurement in RCT and LOS. These data formed the basis for a group discussion at a Nominal Group Technique meeting held in Jersey City, New Jersey, USA, in March 2016. Twelve PRP and 12 physicians came to a consensus on a preliminary core domain set through a moderated discussion. The preliminary core domain set was then proposed at the OMERACT meeting in Whistler, British Columbia, Canada, in May 2016. The final core domain set (Figure 1) included 3 parts: an inner circle (should be measured in all RCT and LOS), a middle circle (important, but not mandatory), and the outer circle that represents the research agenda. The inner circle includes musculoskeletal (MSK) disease activity (peripheral arthritis, enthesitis, dactylitis, and spine symptoms), skin disease activity (skin psoriasis and nail dystrophy), pain, patient's global assessment, physical function, health-related quality of life, fatigue, and systemic inflammation. The middle circle included economic cost, emotional well-being, participation, and structural damage. Finally, stiffness, independence, treatment burden, and sleep were included in the research agenda. Some domains included in the 2016 core domain set were also present in the 2006 and 2014 Core Domain Sets, some moved from the outer circle, and others were added (Figure 1 shows these changes).

Having achieved ratification of the core domain set, the next step for the PsA working group is to select outcome measurement instruments. One of the issues raised at
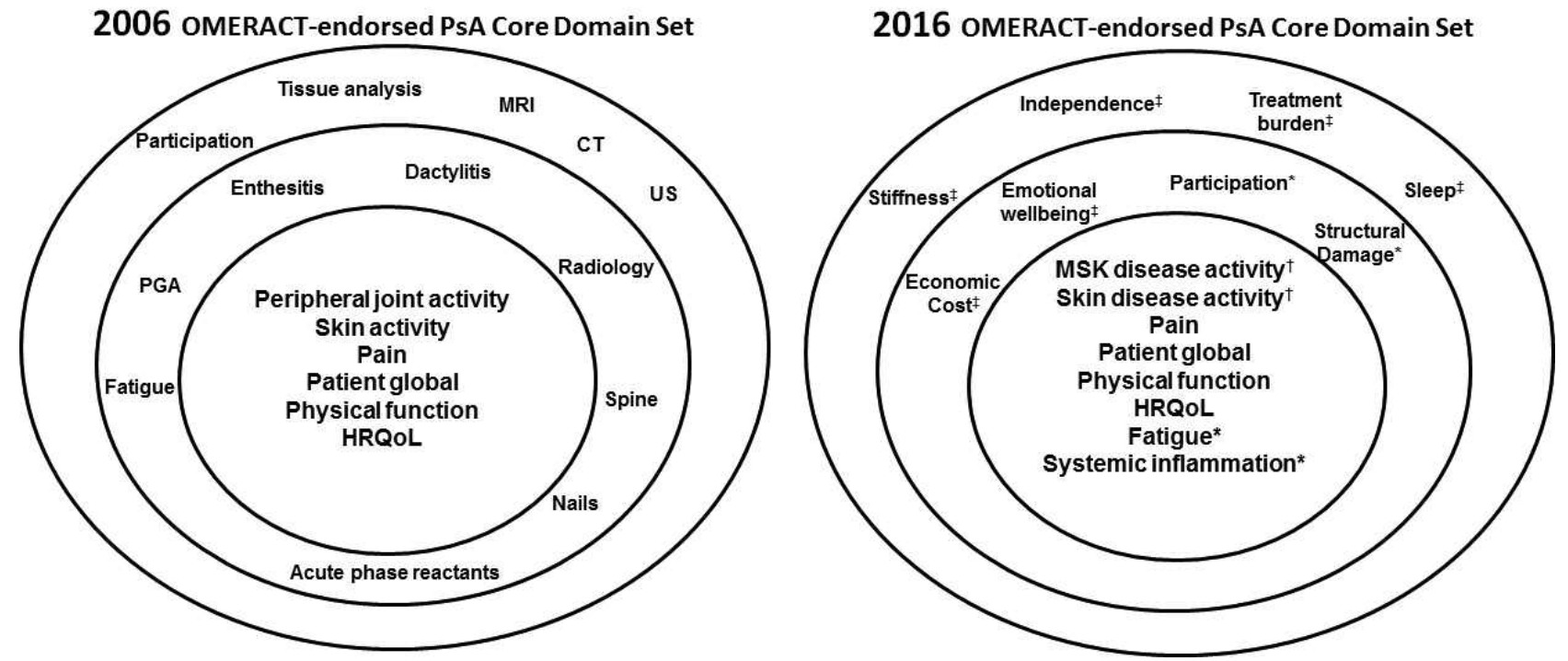

Figure 1. The 2006 and 2016 GRAPPA-OMERACT PsA Core Domain Sets. Adapted from Orbai, et al. Ann Rheum Dis 2016 Sep 9 (E-pub ahead of print); with permission. $*$ In the 2016 core domain set (right), domains that moved from 1 of the outer circles to either the middle or inner circle. ${ }^{\dagger}$ MSK disease activity (now includes peripheral arthritis, enthesitis, dactylitis, and spine symptoms) and skin disease activity (psoriasis and nail dystrophy) were redefined. $\doteqdot$ New additions to the set. GRAPPA: Group for Research and Assessment of Psoriasis and Psoriatic Arthritis; OMERACT: Outcome Measures in Rheumatology; PsA: psoriatic arthritis; MSK: musculoskeletal; MRI: magnetic resonance imaging; CT: computed tomography; US: ultrasound; PGA: physician's global assessment; HRQoL: health-related quality of life.

Personal non-commercial use only. The Journal of Rheumatology Copyright $@$ 2017. All rights reserved 
OMERACT and again at the GRAPPA meeting was the number of domains included within the core domain set. Identifying the full set even within the inner circle is a daunting task. It is important to recognize that each domain will not necessarily need to be measured by an individual instrument. Most recent RCT are already measuring these domains $^{8}$. In fact, among the 8 most recently conducted RCT, most of these domains were identified, although fatigue, participation, and spine symptoms are less commonly measured (Table 1).

\section{PsA Core Set Working Group Meeting}

During this meeting, the working group discussed and reviewed the organization of work streams to tackle the development of the PsA Core Outcome Measurement Set (Figure 2). Each work stream included at least 2 PRP. A series of systematic literature reviews are ongoing to assess measurement properties of candidate instruments, including patient-reported outcomes assessing skin and joint disease activity, fatigue, pain, patient's global assessment,

Table 1. Core domains measured and reported in recent randomized controlled trials (1-8).

\begin{tabular}{lcccccccc}
\hline Domains & 1 & 2 & 3 & 4 & 5 & 6 & 7 & 8 \\
\hline Peripheral arthritis & $\mathrm{X}$ & $\mathrm{X}$ & $\mathrm{X}$ & $\mathrm{X}$ & $\mathrm{X}$ & $\mathrm{X}$ & $\mathrm{X}$ & $\mathrm{X}$ \\
Skin disease & $\mathrm{X}$ & $\mathrm{X}$ & $\mathrm{X}$ & $\mathrm{X}$ & $\mathrm{X}$ & $\mathrm{X}$ & $\mathrm{X}$ & $\mathrm{X}$ \\
Enthesitis & $\mathrm{X}$ & $\mathrm{X}$ & $\mathrm{X}$ & $\mathrm{X}$ & $\mathrm{X}$ & $\mathrm{X}$ & $\mathrm{X}$ & $\mathrm{X}$ \\
Dactylitis & $\mathrm{X}$ & $\mathrm{X}$ & $\mathrm{X}$ & $\mathrm{X}$ & $\mathrm{X}$ & $\mathrm{X}$ & $\mathrm{X}$ & $\mathrm{X}$ \\
Health-related quality & & & & & & & & \\
$\quad$ of life & $\mathrm{X}$ & $\mathrm{X}$ & $\mathrm{X}$ & $\mathrm{X}$ & $\mathrm{X}$ & $\mathrm{X}$ & $\mathrm{X}$ & $\mathrm{X}$ \\
Physical function & $\mathrm{X}$ & $\mathrm{X}$ & $\mathrm{X}$ & $\mathrm{X}$ & $\mathrm{X}$ & $\mathrm{X}$ & $\mathrm{X}$ & $\mathrm{X}$ \\
Systemic inflammation & & $\mathrm{X}$ & $\mathrm{X}$ & $\mathrm{X}$ & $\mathrm{X}$ & $\mathrm{X}$ & $\mathrm{X}$ & $\mathrm{X}$ \\
Structural damage & $\mathrm{X}$ & $\mathrm{X}$ & & & & $\mathrm{X}$ & $\mathrm{X}$ & \\
Nail disease & $\mathrm{X}$ & $\mathrm{X}$ & & & & $\mathrm{X}$ & $\mathrm{X}$ & \\
Spine symptoms & $\mathrm{X}$ & & $\mathrm{X}$ & $\mathrm{X}$ & & & & \\
Fatigue & & & & $\mathrm{X}$ & & $\mathrm{X}$ & $\mathrm{X}$ & \\
Participation & & & & & & & $\mathrm{X}$ & \\
& & & & & & & & \\
\hline
\end{tabular}

health-related quality of life, participation, and emotional well-being; physical examination methods for assessing MSK and skin disease activity; systemic inflammation; imaging modalities to assess structural damage and disease activity; and composite disease activity measures. A qualitative assessment of the feasibility and the content validity of available instruments from the perspective of patients and physicians has been launched. Simultaneously, instrument assessments are being performed within RCT and LOS. These 3 efforts will produce data about the measurement performance of each instrument. These data will be presented and discussed in a workshop and breakout groups at the next GRAPPA annual meeting, after which the group may realize that additional data are needed. The working group will then refine the data obtained and structure patient and physician Delphi surveys using methods similar to those used in the development of the core domain set. The patient and physician Delphis will be used to achieve consensus on the optimal instruments to address some, if not all, of the core domains. If needed, an in-person consensus meeting will be held following the Delphi. The working group aims to present a preliminary core outcome measurement set for discussion and voting at the next OMERACT meeting in May 2018.

\section{DISCUSSION}

As the number of new therapies for psoriasis and PsA increases, it has become more important to understand how to best measure disease activity, effect, and longterm patient outcomes. Additionally, standardizing outcome measurement among RCT and LOS will assist patients, clinicians, and others in better evaluating the evidence available for a particular treatment. To this end, patients, rheumatologists, dermatologists, and methodologists are working together through GRAPPA, OMERACT, and the International Dermatology Outcome Measurers to develop and standardize core outcome measurement sets for psoriatic disease.

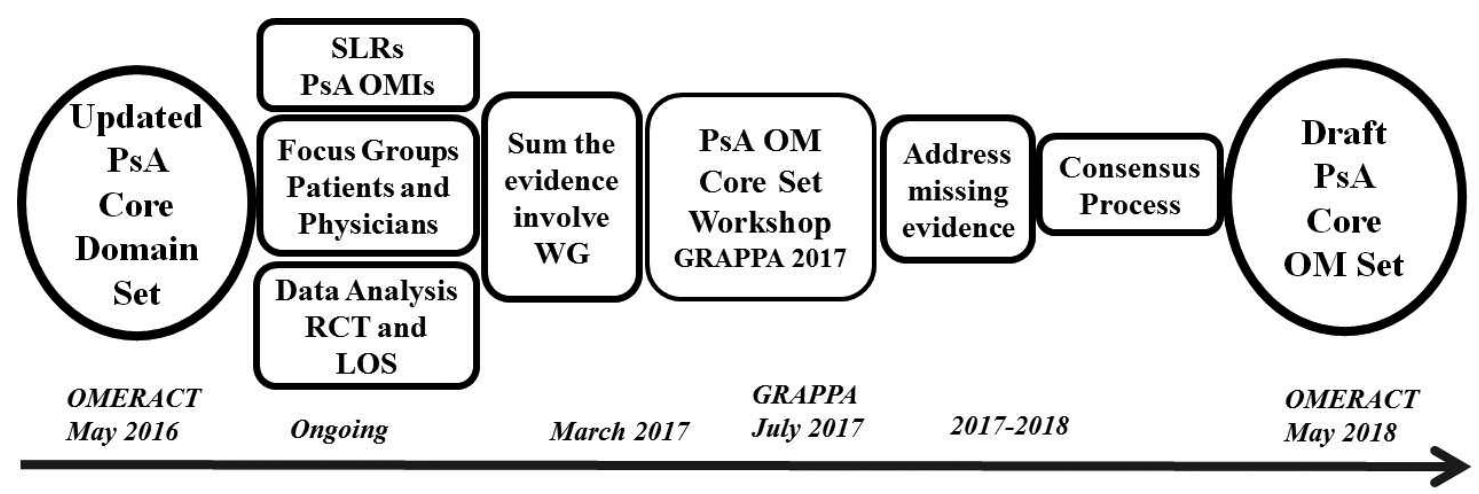

Figure 2. Road map for developing the PsA Core Outcome Measurement Set. Work streams are listed in chronological order. PsA: psoriatic arthritis; SLR: systematic literature review; OMI: outcome measurement instruments; RCT: randomized controlled trials; LOS: longitudinal observational studies; WG: working group; GRAPPA: Group for Research and Assessment of Psoriasis and Psoriatic Arthritis; OMERACT: Outcome Measures in Rheumatology.

Personal non-commercial use only. The Journal of Rheumatology Copyright @ 2017 . All rights reserved. 


\section{ACKNOWLEDGMENT}

We acknowledge all members of the GRAPPA-OMERACT PsA working group, which includes the authors along with Laure Gossec, Pil Hoejgaard, Neil McHugh, Robin Christensen, and Katy Leung, who were unable to attend the GRAPPA meeting, as well as Rodrigo Firmino.

\section{REFERENCES}

1. Gladman DD. Clinical features and diagnostic considerations in psoriatic arthritis. Rheum Dis Clin North Am 2015;41:569-79.

2. Gossec L, de Wit M, Kiltz U, Braun J, Kalyoncu U, Scrivo R, et al; EULAR PsAID Taskforce. A patient-derived and patient-reported outcome measure for assessing psoriatic arthritis: elaboration and preliminary validation of the Psoriatic Arthritis Impact of Disease (PsAID) questionnaire, a 13-country EULAR initiative. Ann Rheum Dis 2014;73:1012-9.

3. Gladman DD, Mease PJ, Strand V, Healy P, Helliwell PS, Fitzgerald $\mathrm{O}$, et al. Consensus on a core set of domains for psoriatic arthritis. J Rheumatol 2007;34:1167-70.
4. Tillett W, Eder L, Goel N, De Wit M, Gladman DD, FitzGerald O, et al. Enhanced patient involvement and the need to revise the core set - report from the Psoriatic Arthritis Working Group at OMERACT 2014. J Rheumatol 2015;42:2198-203.

5. Boers M, Kirwan JR, Wells G, Beaton D, Gossec L, d'Agostino MA, et al. Developing core outcome measurement sets for clinical trials: OMERACT filter 2.0. J Clin Epidemiol 2014;67:745-53.

6. Orbai AM, Mease PJ, de Wit M, Kalyoncu U, Campbell W, Tillett W, et al. Report of the GRAPPA-OMERACT Psoriatic Arthritis Working Group from the GRAPPA 2015 Annual Meeting. J Rheumatol 2016;43:965-9.

7. Orbai AM, de Wit M, Mease P, Shea JA, Gossec L, Leung YY, et al. International patient and physician consensus on a psoriatic arthritis core outcome set for clinical trials. Ann Rheum Dis 2016 Sep 9 (E-pub ahead of print).

8. Kalyoncu U, Ogdie A, Campbell W, Bingham CO 3rd, de Wit M, Gladman DD, et al. Systematic literature review of domains assessed in psoriatic arthritis to inform the update of the psoriatic arthritis core domain set. RMD Open 2016;2:e00217. 